\title{
Analysis of gluten proteins composition during grain filling in two durum wheat cultivars submitted to two water regimes
}

\author{
Marcella Michela Giuliani, Michele Andrea De Santis, Marianna Pompa, Luigia Giuzio, \\ Zina Flagella
}

Dipartimento di Scienze Agrarie, degli Alimenti e dell'Ambiente, Università di Foggia, Italy

\begin{abstract}
Durum wheat (Triticum turgidum L. subsp. durum) is one of the major crops in the Mediterranean basin, where water stress often occurs during grain filling which represents a critical stage for the synthesis and accumulation of storage proteins (gliadins and glutenins). The aim of the study is to evaluate, by two-dimensional gel electrophoresis (2DE SDS-PAGE), the storage proteins composition of two durum wheat cultivars (Ciccio and Svevo) cultivated in a growth chamber under two different water regimes (control and water deficit). At milk stage and physiological maturity, gluten proteins have been extracted and separated by 2DE SDS-PAGE. The analysis of the gels was performed by the software ImageMaster 2D Platinum (Amersham). The results showed differences in protein expression within the different gel regions between water regimes and cultivars; under water deficit the rate of protein accumulation was faster for all the protein regions, either at milk and physiological stage. Protein accumulation within high molecular weight $(\mathrm{H})$ region resulted faster in Ciccio than in Svevo mainly in the control treatment. In the low molecular weight region between 48 and $35 \mathrm{kDa}$ (L 48-35), the cultivar Ciccio showed a higher protein expression than Svevo. Furthermore under water deficit a marked increase in $\mathrm{H}$ region volume and a decrease in the L 48-35 region was observed only for Svevo; instead in
\end{abstract}

Correspondence: Zina Flagella, Dipartimento di Scienze Agrarie, degli Alimenti e dell'Ambiente, Università di Foggia, via Napoli 25, 71121 Foggia, Italy.

Tel. +39.0881589220 - Fax: +39.0881589502 .

E-mail: zina.flagella@unifg.it

Key words: durum wheat, gluten proteins, grain filling, water deficit.

Acknowledgments: this work was carried out in the framework of the project MiUR-AGROGEN.

Conference presentation: SIA XLII Congress, Reggio Calabria, 2013.

Received for publication: 14 October 2013.

Revision received: 11 December 2013.

Accepted for publication: 20 December 2013.

(C) Copyright M.M.Giuliani et al., 2014

Licensee PAGEPress, Italy

Italian Journal of Agronomy 2014; 9:558

doi:10.4081/ija.2014.558

This article is distributed under the terms of the Creative Commons Attribution Noncommercial License (by-nc 3.0) which permits any noncommercial use, distribution, and reproduction in any medium, provided the original author(s) and source are credited.
Ciccio no change was observed showing this cultivar a greater stability on changing water regime. Further studies by the use of mass spectrometry are necessary to identify specific peptides relative to drought stress during grain filling as well as to investigate the relationships with technological quality.

\section{Introduction}

Durum wheat (Triticum turgidum L. subsp. durum) is one of the most important crops in Mediterranean area due to its unique suitability for pasta production. Prolamins, accounting for $80 \%$ of grain wheat proteins, are the major constituents of gluten and they are responsible for dough quality. They are conventionally divided into two groups, the monomeric gliadins ( $\alpha / \beta$-, $\gamma$-, and $\omega$-subunits) and the polymeric glutenins (high and low molecular weight subunits, HMW-GS and LMW-GS, respectively), which together determine pasta-making quality, being responsible for dough viscosity and elasticity properties, respectively (Shewry and Halford, 2002). In the field, unfavourable environmental conditions may occur at any time during wheat growing season with intensity and duration affecting several processes during the whole plant life cycle. Understanding how environmental treatments affect the timing of grain developmental processes is of fundamental importance to pursue wheat quality because during this period the protein synthesis occurs. To study the effects of individual environmental factors on wheat grain development and in particular on wheat protein synthesis, several studies under controlled environment have been carried out. In particular recent studies illustrate how high temperatures and drought accelerate grain development (Altenbach et al., 2003; Hurkman and Wood, 2011) thus making more difficult to detect changes in protein accumulation in response to environmental factors. To better investigate the effects of environment on proteins and genes that may be involved in determining yield and quality, proteomic and transcriptomic approaches result useful (Altenbach, 2012). However, also due to the various post-translational modifications of proteins that occur as grain develops, the accumulated amounts of a large proportion of proteins are often poorly correlated with their corresponding mRNAs in expression profiles; for this reason a proteomic approach can be more valuable in monitoring developmental profiles (Guo et al., 2012).

Proteomic approach is a powerful method to identify and quantify the large number of proteins in biological samples (Skylas et al., 2005; Finnie et al., 2011). Proteomic analysis of grain wheat proteins is difficult because of the wide range of protein expressed in the kernel. Moreover, relative to the gluten proteins, gliadins and glutenins consist of many closely related proteins with similar molecular weights and isoelectric points and therefore considerably overlap in twodimensional electrophoresis (2-DE). Additionally, proteomic data on the gluten proteins is limited, also because it has been very challenging to identify these proteins by mass spectrometry (MS) (Altenbach, 2012). Recently, several groups have used proteomic approach to 
determine the environmental effect on the accumulation of grain protein during grain filling. However, the most of the research focused on metabolic wheat grain proteins, while fewer are the studies on the storage proteins, in particular in durum wheat. Saint Pierre et al. (2008) studying 9 wheat genotypes, found that the percentage of gliadins increased more rapidly than glutenins as flour protein increased; since maximum rate of synthesis of glutenins was reported to occur later than maximum rate of gliadins, the authors concluded that a late water stress could have more detrimental effect on the synthesis of glutenins than of gliadins. Also in durum wheat Fois et al. (2011) reported that the ratio gliadins/glutenins decreased linearly as days after anthesis increased, being the synthesis of gliadins higher in the earlier stage of maturation, whereas glutenins accumulate more rapidly towards the latter stage.

The aim of the present study was to deep insight into genetic and environmental influences on gluten protein accumulation of durum wheat during grain filling which is a critical stage in determining grain quality. To this aim the difference in gluten proteins composition between two phenological stages during grain filling was carried out by $2 \mathrm{DE}$ in two-durum wheat cultivars submitted to two water regimes.

\section{Materials and methods}

\section{Plant material and growth conditions}

Two durum wheat cultivars, Ciccio and Svevo, were grown in a growth chamber in 2009 under controlled conditions of temperature, humidity and photoperiod. From sowing to physiological maturity the maximum temperatures varied from $6^{\circ} \mathrm{C}$ to $28^{\circ} \mathrm{C}$ and the minimum from $5^{\circ} \mathrm{C}$ to $22^{\circ} \mathrm{C}$, the photoperiod from $10 / 14 \mathrm{~h}$ light/dark to $16 / 8 \mathrm{~h}$ light/dark, and the relative humidity from $70 \%$ to $50 \%$. The two cultivars differed for gluten quality; in particular, on the bach used for sowing, Ciccio showed a gluten index value of 84 , which was almost twice compared with 39 obtained from Svevo. A completely randomized design with three replications and three factors was adopted (cultivar, water regime and phenological stage). Seeds were sown, on February 2, in pots of $0.055 \mathrm{~m}^{2}$ with a seeding density of 250 seeds $\mathrm{m}^{-2}$ (14 seeds per pot); after emergence, seed density was uniformed at 11 seeds per plot. The soil mixture used consisted of sandy clay loam soil, sand and peat in $6: 3: 1$ ratio, with a field capacity of $26.9 \%$ and a wilting point of $16.4 \%$. At sowing date, phosphorus fertilizer was applied at a rate of $9 \mathrm{~g} \mathrm{~m}^{-2}$ as diammonium phosphate; instead nitrogen fertilizer $\left(12 \mathrm{~g} \mathrm{~m}^{-2}\right)$ was applied in three different times: $3.5 \mathrm{~g} \mathrm{~m}^{-2}$ at sowing together with phosphorous, $6.5 \mathrm{~g} \mathrm{~m}^{-2}$ at tillering and $2 \mathrm{~g} \mathrm{~m}^{-2}$ at pre-anthesis as ammonium nitrate. The irrigation treatment, until anthesis, consisted in bringing soil moisture up to field capacity whenever the threshold of $50 \%$ of available soil water content was reached. From anthesis (73 days after sowing) onwards two different water regimes were adopted. Soil moisture was replenished to $70 \%$ of the available water in the stressed thesis and to field capacity in the control. Relative water content (RWC) was measured according to Borrelli et al. (2011) at milk stage, in order to evaluate plant water status. In the stressed condition a significant RWC decrease was observed for both cultivars (50\% and 38\% decrease for Ciccio and Svevo, respectively). At milk stage (15 days post anthesis-DPA in stressed and 19 DPA in control) and at physiological stage (30 and $33 \mathrm{DPA}$ ) kernels were harvested. In both cultivars the stressed treatment determined a yield decrease of about $47 \%$.

\section{Storage protein extraction}

Storage proteins were extracted according to Hurkman and Tanaka
(2004) from $50 \mathrm{mg}$ of grain samples at milk stage and at physiological stage with $\mathrm{KCl}$ buffer $(100 \mathrm{mM} \mathrm{KCl}, 50 \mathrm{mM}$ Tris-HCl pH 7.8, $5 \mathrm{mM}$ EDTA). Suspension was incubated on ice for $5 \mathrm{~min}$, with intermittent shaking, and centrifuged at $14,500 \mathrm{~g}$ for $15 \mathrm{~min}$ at $4^{\circ} \mathrm{C}$ to separate soluble (supernatant) from insoluble fraction (pellet). Afterwards, storage proteins were extracted from the pellet by $800 \mu \mathrm{L}$ of SDS buffer $(2 \%$ SDS, $10 \%$ glycerol, $50 \mathrm{mM}$ DTT, $40 \mathrm{mM}$ Tris- $\mathrm{HCl}, \mathrm{pH}$ 6.8). Proteins were precipitated by addition of $4 \mathrm{vol}$ of cold acetone $\left(-20^{\circ} \mathrm{C}\right)$ to remove the SDS, which interferes with protein determination and prevents separation of proteins by isoelectric focusing (IEF). After an incubation overnight at $-20^{\circ} \mathrm{C}$ and a double centrifugation at $16,000 \mathrm{rpm}$ for 10 min at room temperature, acetone was removed. Protein to be analyzed by IEF was solubilized in urea buffer ( $8 \mathrm{M}$ urea, $2 \%$ Triton X-100, $0.03 \%$ DTT, $0.04 \%$ BPB, 0.5\% IPG buffer). The protein concentration was determined using the Biuret method, with bovine serum albumin as a standard.

\section{Two-dimensional gel electrophoresis analysis}

Storage proteins were separated by IEF X SDS-PAGE. Samples containing $200 \mu \mathrm{g}$ of storage proteins were loaded on each IEF gel. Immobiline DryStrips (pH 3-10, 13 cm length; GE Healthcare BioSciences AB, Uppsala, Sweden) were used to perform first-dimension electrophoresis after rehydration using the Ettan IPGphor 3 isoelectric focusing system (GE Healthcare Bio-Sciences AB) according to Ferrante et al. (2006). The separation in the second dimension was carried out with a SE 600 apparatus (Hoefer, Inc., Holliston, MA, USA). The strips were equilibrated and then loaded onto $18 \times 16 \mathrm{~cm}$ vertical polyacrylamide SDS-PAGE gels (T, 12\%; C, 1.28\%), $1 \mathrm{~mm}$ thick. Separation of both proteins and molecular weight markers (GE Healthcare BioSciences $\mathrm{AB}$ ) was performed at $30 \mathrm{~mA}$ per gel at $10^{\circ} \mathrm{C}$. Staining was performed according to Neuhoff et al. (1998) with a destaining in tap water. Four replicates were performed on two biological grain samples, for a total of 32 gels. Destained gels were analyzed using ImageMaster 2D Platinum 6.0 software (GE Healthcare Bio-Sciences AB), and the expression levels of protein spots on 2-DE gels were determined by protein abundance (vol\%). To better discriminate cultivars and environmental differences the 2DE gels were subdivided into four regions on the basis of protein molecular weight as reported also in Pompa et al. (2013): the high molecular weight $(\mathrm{H})$ region $(>60 \mathrm{kDa})$, the intermediate (I) region $(60-48 \mathrm{kDa})$, the $48-35 \mathrm{kDa}$ low molecular weight region (L 48-35) and the $<35 \mathrm{kDa}$ low molecular weight region $(\mathrm{L}<35)$. The data were analyzed using the analysis of variance (ANOVA) procedure of the M-stat C statistical package (Crop Soil Sciences Department, Michigan State University). The significant differences among the mean values were calculated following Tukey's test.

\section{Results and discussion}

The 2-DE gels were highly reproducible and showed well-resolved spots without streaming. The number of spots, the percentage volume of the four gel regions and the ratio volume between the two developmental stages for all the theses under study are shown in Table 1. Compared with irrigated treatment the stressed one reached the milk and the physiological stage earlier (15 DPA vs 19 DPA and 30 vs 33 DPA, respectively). This result is in agreement with several studies under controlled environment, illustrating how high temperatures and drought accelerate grain development (Altenbach et al., 2003; Hurkman and Wood, 2011). In agreement with Shewry and Halford (2002) the percentage volume of the different gel region was on average $11.3 \%$ for the $\mathrm{H}$ region and $82.9 \%$ for the $\mathrm{L}$ region ( $48-35$ and $<35 \mathrm{kDa}$ ). 
Concerning the ratio volume between the two phenological stages, a different behavior was observed for the different gel regions. As for $\mathrm{H}$ region, in the literature it is reported that the two cultivars under study show the presence of Glu-B1 $b$ allele coding for protein subunits HMWGS 7 and 8 associated with favorable dough properties (Gianibelli et al., 2001; Giuliani et al., 2012; Mamone et al., 2009; Yan et al., 2009). In the control treatment the increase in protein expression observed at physiological stage was more marked in Ciccio (Table 1). It seems that the accumulation of glutenin subunits in the $\mathrm{H}$ region began earlier in Svevo than in Ciccio having the first one a higher protein volume than Ciccio at milk stage. Moreover the final protein volume at physiological stage was about 39\% higher for Ciccio in the control and 35\% higher for Svevo in the stressed condition (data not shown).
As for I region the protein expression increase observed at physiological stage was more marked in stressed condition, especially for Ciccio. In this region both in Ciccio and in Svevo several spots, specific for milk stage, resulted more concentrated in the gel zone near $\mathrm{pH} 3$, while at physiological stage the specific spots appeared in the basic zone of the gel (Figure 1) making us assume a possible change in the protein isoelectric point (pI) during grain filling. According to our results also Guo et al. (2012) reported the presence of proteins near the acid zone of the gel in the early developmental stage, with the number of basic proteins increasing at maturity. Moreover in both cultivars there was one spot that seems to be a master spot at the beginning of a spot train. For both cultivars the spot train was characterized by several spots having the same molecular weight but different pI values,

Table 1. Overall number of spots and percentage volume of the gel regions and ratio volume between physiological (30 and 33 DPA) and milk (15 and 19 DPA) stage.

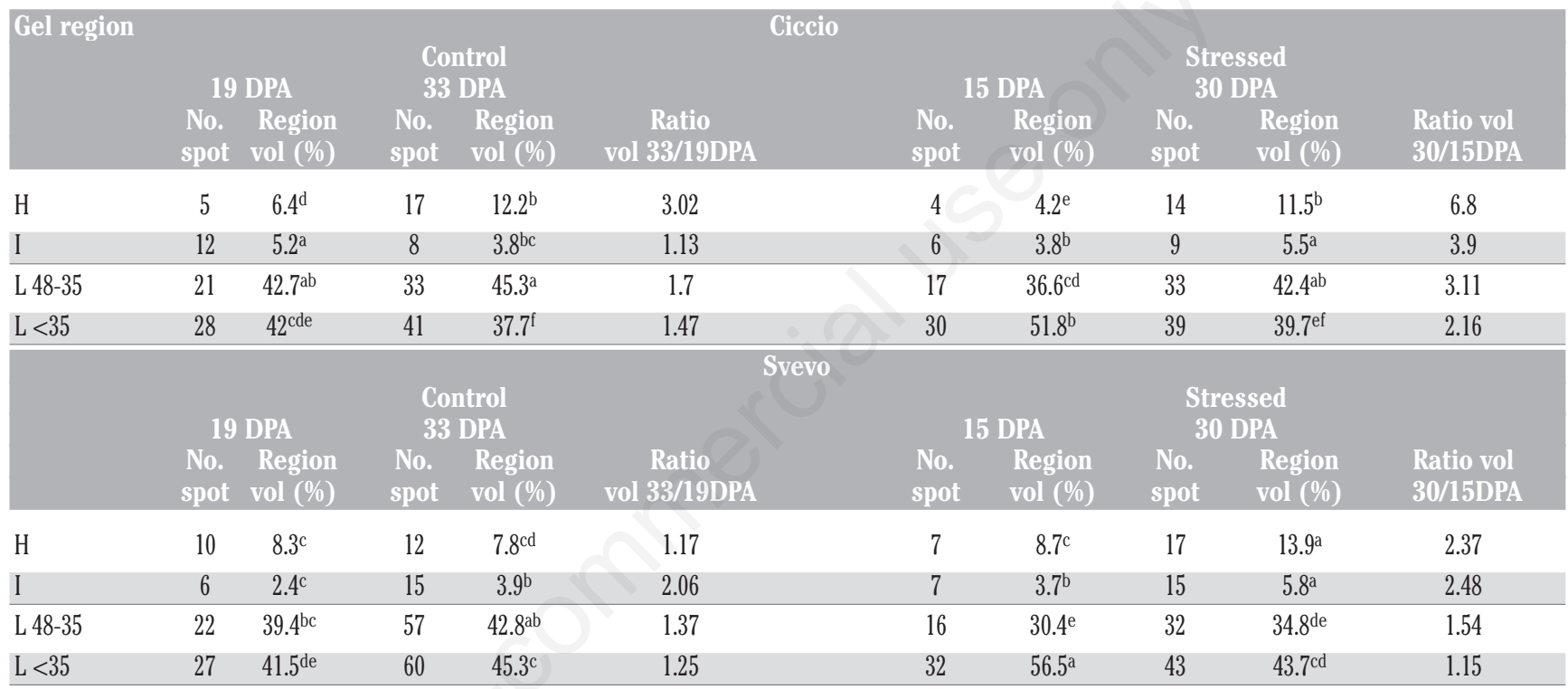

a,b,c,d,e,f'Different letters indicate significant differences at $0.01 \mathrm{P}$ level according to Tukey's test.

A $\mathrm{pH} 3$

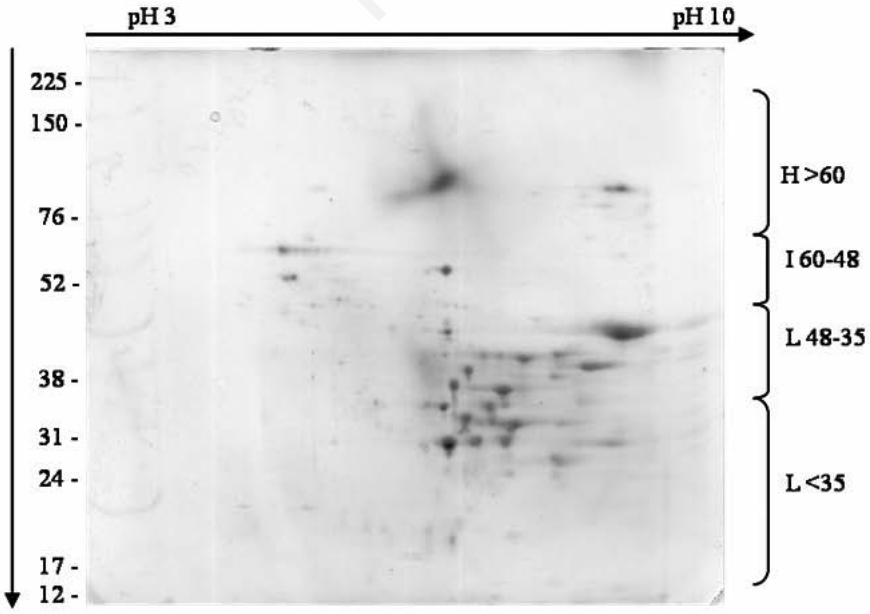

B

$\mathrm{pH} 3 \quad \mathrm{pH} 10$

Figure 1. Gluten protein 2DE gels (IEF $\times$ SDS - PAGE) of milk (A) and physiological stage (B). 
shifted toward basic $\mathrm{pH}$ (Figure 1). In a recent study on three durum wheat cultivars (Ofanto, Latino and Simeto) Pompa et al. (2013) identified the same spot train as the globulin 3 protein codified by the Glo3A gene. Globulin-like proteins are nonprolamines similar to 7S vicilinlike proteins, and functioning as storage proteins; they are incorporated unspecifically into the gluten network, suggesting that their role in the gluten agglomeration is rather aspecific (Altenbach et al., 2009). Pompa et al. (2013) found a higher expression of this globulin under high temperature condition. Also in this study the spot train seems to be environmentally dependent since it was over expressed under drought condition in both cultivars. These results are in agreement with Altenbach (2012) and Laino et al. (2010) who reported an increase in the globulin-2 amount during grain development under high temperatures in both Triticum aestivum and Triticum turgidum subsp. durum, and with Jiang et al. (2012) who found an over expression of different globulins in response to water deficit during grain development.

As for L 48-35 region the increase in protein expression at physiological stage was more marked for Ciccio and in stressed condition. For this gel region the final protein volume at physiological stage was about $53 \%$ and $30 \%$ higher for Ciccio in control and stressed condition, respectively (data not shown). Moreover, under stress conditions Svevo showed a decrease in this region volume (\%), while in Ciccio no change was observed (Table 1). It is known that in the $\mathrm{L}$ 48-35 region there is a higher concentration of LMW type 1 or 2 and of some LMW glutenins codified by GluB3 locus associated to the dough quality. In particular in the literature it is reported that both Ciccio and Svevo show the LMW-2 (Fois et al., 2011; Giuliani et al., 2012), which gives superior grain quality characteristics than the allelic group LMW-1.

Finally, also for $\mathrm{L}<35$ region, including most of gliadins, both cultivars showed an increase in protein accumulation at physiological stage, more marked under stressed condition in Ciccio. This increase was already reported in response to environmental factors, as high temperature (Majoul et al., 2003; Dupont et al., 2006a, 2006b).

\section{Conclusions}

The results showed differences in gluten proteins expression during grain filling between both the two cultivars and the two water regimes investigated. Under water deficit the rate of protein accumulation was faster in all gel regions, especially for Ciccio. Also an increase in I region accumulation was observed under water stress for both cultivars, which might be ascribable to an increase in Globulin 3 protein, whose expression was reported to be stimulated under environmental stresses.

Concerning cultivar performance, in the L 48-35 region the final protein volume at physiological stage was always higher for Ciccio; this result might be related to the higher gluten index values observed in this cultivar. Moreover Ciccio showed a greater stability in protein composition across water regimes, differently from Svevo that showed a marked increase in $\mathrm{H}$ region volume and a decrease in the $\mathrm{L} 48-35$ region under water stress.

These results showing the interaction between genotype and environment across different water regimes in relation to gluten proteins composition appear of particular interest. In fact, the stability in durum wheat gluten composition and quality is a desirable trait for market requirements. Further studies have to be done by a proteomic approach in order to broaden the investigation to more genotypes and environments and to deep insight into the relationships between gluten protein composition and durum wheat technological quality.

\section{References}

Altenbach SB, 2012. New insights into the effects of high temperature, drought and post-anthesis fertilizer on wheat grain development. J. Cereal Sci. 56:39-50.

Altenbach SB, Dupont FM, Kothari KM, Chan R, Johnson EL, Lieu D, 2003. Temperature, water and fertilizer influence the timing of key events during grain development in a US spring wheat. J. Cereal Sci. 37: 9-20.

Altenbach SB, Tanaka CK, Hurkman WJ, Vensel WH, 2009. Expression of globulin-2, a member of the cupin superfamily of proteins with similarity to known food allergens, is increased under high temperature regimens during wheat grain development. J. Cereal Sci. 49:47-54.

Borrelli GM, Ficco DBM, Giuzio L, Pompa M, Cattivelli L, Flagella Z, 2011. Durum wheat salt tolerance in relation to physiological, yield and quality characters. Cereal Res. Comm. 39:525-34.

Dupont FM, Hurkman WJ, Vensel WH, Chan R, Lopez R, Tanaka CK, Altenbach SB, 2006a. Differential accumulation of sulfur rich and sulphur-poor wheat flour proteins is affected by temperature and mineral nutrition during grain development. J. Cereal Sci. 44:101-12.

Dupont FM, Hurkman WJ, Vensel WH, Tanaka CK, Kothari KM, Chung OK, Altenbach SB, 2006b. Protein accumulation and composition in wheat grains: effects of mineral nutrients and high temperature. Eur. J. Agron. 25:96-107.

Ferrante P, Masci S, D’Ovidio R, Lafiandra D, Volpi C, Mattei BA, 2006. A proteomic approach to verify in vivo expression of a novel $\alpha$-gliadin containing an extra cysteine residue. Proteomics 6:1908-14.

Finnie C, Sultan A, Grasser KD, 2011. From protein catalogues towards targeted proteomics approaches in cereal grains. Phytochemistry 72:1145-53.

Fois S, Schlichting L, Marchylo B, Dexter J, Motzo R, Giunta F, 2011. Environmental conditions affect semolina quality in durum wheat (Triticum turgidum ssp. durum L.) cultivars with different gluten strength and gluten protein composition. J. Sci. Food Agric. 91:2664-73.

Gianibelli MC, Larroque OR, MacRitchie F, Wrigley CW, 2001. Biochemical, genetic, and molecular characterization of wheat glutenin and its component subunits. Cereal Chem 78:635-46.

Giuliani MM, Pompa M, Palermo C, Giuzio L, Centonze D, Flagella Z, 2012. Effect of water stress on storage protein composition of two durum wheat varieties evaluated by a proteomic approach. pp 488489 in Proc. 12th Congr. European Society for Agronomy, Helsinki, Finland.

Guo G, Lu G, Yan Y, Subburaj S, Ge P, Li X, Hu Y, Yan Y, 2012. Proteome characterization of developing grains in bread wheat cultivars (Triticum aestivum L.). BMC Plant Biol. 12:147.

Hurkman WJ, Tanaka CK, 2004. Improved methods for separation of wheat endosperm proteins and analysis by two-dimensional gel electrophoresis. J. Cereal Sci. 40:295-9.

Hurkman WJ, Wood DF, 2011. High temperature during grain fill alters the morphology of protein and starch deposits in the starchy endosperm cells of developing wheat (Triticum aestivum L.) grain. J. Agric. Food Chem. 59:4938-46.

Jiang SS, Liang SS, Li X, Wang SL, Lu DW, Ma CY, Li XH, Ma WJ, Yan YM, 2012. Wheat drought-responsive grain proteome analysis by linear and nonlinear 2-DE and MALDI-TOF mass spectrometry. Int. J. Mol. Sci. 13:16065-83.

Laino P, Shelton D, Finnie C, De Leonardis AM, Mastrangelo AM, Svensson B, Lafiandra D, Masci S, 2010. Comparative proteome analysis of metabolic proteins from seeds of durum wheat (cv. Svevo) subjected to heat stress. Proteomics 10:2359-68. 
Mamone G, De Caro S, Di Luccia A, Addeo F, Ferranti P, 2009. Proteomic-based analytical approach for the characterization of glutenin subunits in durum wheat. J. Mass. Spectrom. 44:1709-23.

Majoul T, Bancel, E, Triboï E, Ben Hamida J, Branlard G, 2003. Proteomic analysis of the effect of heat stress on hexaploid wheat grain: characterization of heat responsive proteins from total endosperm. Proteomics 3:175-83.

Neuhoff V, Arold N, Taube D, Ehrhardt W, 1988. Improved staining of proteins in polyacrylamide gels including isoelectric focusing gels with clear background at nanogram sensitivity using Coomassie Brilliant Blue G-250 and R-250. Electrophoresis 9:255-62.

Pompa M, Giuliani MM, Palermo C, Agriesti F, Centonze D, Flagella Z, 2013. Comparative analysis of gluten proteins in three durum wheat cultivars by a proteomic approach. J. Agric. Food Chem. 61:2606-17. Saint Pierre C, Peterson CJ, Ross AS, Ohm JB, Verhoeven MC, Larson M, Hoefer B, 2008. Winter wheat genotypes under different levels of nitrogen and water stress: changes in grain protein composition. J. Cereal Sci. 47:407-16.

Shewry PR, Halford NG, 2002. Cereal seed storage proteins: structures, properties and role in grain utilization. J. Exp. Bot. 53:947-58.

Skylas DJ, Van Dyk D, Wrigley CW, 2005. Proteomics of wheat grain. J. Cereal Sci. 41:165-79.

Yan Y, Jiang Y, An XL, Pei YH, Li XH, Zhang YZ, Wang AL, He Z, Xia X, Bekes F, Ma W, 2009. Cloning, expression and functional analysis of HMW glutenin subunit 1 By8 gene from Italy pasta wheat (Triticum turgidum L. ssp. durum). J. Cereal Sci. 50:398-406. 